\title{
IN VITRO RELEASE STUDIES OF CARBAMAZEPINE TABLETS AND BENZOYL METRONIDAZOLE SUSPENSIONS USING THE FLOW-THROUGH CELL APPARATUS AND SIMULATED GASTROINTESTINAL FLUIDS
}

\author{
JOSE RAUL MEDINA*, JONATHAN HERNANDEZ, MARCELA HURTADO \\ Departamento Sistemas Biologicos, Universidad Autonoma Metropolitana-Xochimilco, Mexico City, Mexico \\ Email: rmlopez@correo.xoc.uam.mx
}

Received: 05 Apr 2017, Revised and Accepted: 14 Jun 2017

\begin{abstract}
Objective: To characterize the in vitro release of carbamazepine tablets and benzoyl metronidazole suspensions using the flow-through cell apparatus and simulated gastrointestinal fluids.

Methods: Tegretol ${ }^{\circledR}$ tablets, Flagyl ${ }^{\circledR}$ suspension, and generic formulations of each were tested. Release studies were performed using an automated flow-through cell apparatus. Simulated gastric fluid (with and without pepsin) and simulated intestinal fluid (without pancreatin) at $16 \mathrm{ml} / \mathrm{min}$ and fasted state simulated intestinal fluid at $8 \mathrm{ml} / \mathrm{min}$, all at $37.0 \pm 0.5^{\circ} \mathrm{C}$, were used as dissolution media. The quantity of dissolved carbamazepine and benzoyl metronidazole was determined at 5-min intervals until $60 \mathrm{~min}$ at 285 and $278 \mathrm{~nm}$, respectively. Percentage dissolved at $60 \mathrm{~min}$, mean dissolution time, dissolution efficiency values, and $t_{10 \%}, t_{25 \%}, t_{50 \%}$ and $t_{63.2 \%}$ were calculated. Mean values for all parameters were compared between the reference and generic formulations using Student's $t$-test. Dissolution data were fitted to different kinetic models.
\end{abstract}

Results: Simulated gastric fluid without pepsin showed no discriminative capability for carbamazepine tablets. Significant differences were observed between the reference and generic formulations for almost all parameters $(* \mathrm{P}<0.05)$. In some cases, the logistic model best described the in vitro release of both drugs.

Conclusion: Using an apparatus and media that best simulates the gastrointestinal environment, we identified differences in the rate and extent of dissolution of both drugs that could help to optimise the design of interchangeable formulations. Based on the physicochemical characteristics of carbamazepine and benzoyl metronidazole and the conditions in which the formulations were tested, these differences could be of clinical relevance.

Keywords: Benzoyl metronidazole, Biorelevant media, Carbamazepine, Flow-through cell apparatus, Simulated gastrointestinal fluids, USP Apparatus 4

(C) 2017 The Authors. Published by Innovare Academic Sciences Pvt Ltd. This is an open access article under the CC BY license (http://creativecommons.org/licenses/by/4.0/) DOI: http://dx.doi.org/10.22159/ijap.2017v9i4.18929

\section{INTRODUCTION}

Carbamazepine, an antiepileptic drug with a narrow range of therapeutic efficacy, is widely used to control seizures [1]. Benzoyl metronidazole is an antiparasitic and antibacterial agent $[2,3]$. According to the Biopharmaceutics Classification System, carbamazepine is a Class II drug owing to its low solubility/high permeability; metronidazole is a Class I drug owing to its high solubility/high permeability [4]. However, Kasim et al. [5] have classified metronidazole as a Class III drug (high solubility/low permeability), and a private company specializing in drug delivery studies $[6,7]$ has classified it as a Class IV drug (low solubility/low permeability). Both compounds are manufactured as generic tablets and suspensions, and to determine whether these drugs are safely interchangeable, evaluation of their in vitro release under conditions that simulate the natural environment of the gastrointestinal tract is very important. A generic product refers to a bioequivalent product with the same quality and efficacy as the new drug [8]. In vitro dissolution studies are currently performed with a United States Pharmacopeia (USP) basket (USP Apparatus 1) or paddle apparatus (USP Apparatus 2). An official dissolution test for carbamazepine tablets, using a USP Apparatus 2 at $75 \mathrm{rpm}$ with $900 \mathrm{ml}$ of $1.0 \%$ sodium lauryl sulphate aqueous solution as the dissolution medium, has been reported, but no official dissolution test for benzoyl metronidazole suspension is defined in the USP [9].

Accurately simulating gastrointestinal conditions is essential to adequately predict the in vivo behavior of poorly soluble drugs [10]. For immediate-release dosage forms containing Class II or Class IV drugs, drug solubilization and formulation properties have a substantial effect on in vitro and in vivo dissolution. The in vitro dissolution profiles should be evaluated during drug development using biorelevant tests (using biorelevant media combined with biorelevant hydrodynamics appropriate for the formulation) so that a correlation can be established between the in vitro dissolution and the in vivo performance [11]. Drug absorption may be affected by several physiological factors, including volume and composition of the gastrointestinal fluids, the $\mathrm{pH}$ and buffer capacity of these fluids, digestive enzymes, contraction patterns, and bacterial flora in the gut [12]. Simulated human fluids have been widely used to mimic the natural environment in which the dosage forms will be administered and to evaluate the predictive capability of a dissolution test. Simulated gastric fluid (SGF) with or without pepsin, simulated intestinal fluid (SIF) with or without pancreatin, fasted state simulated intestinal fluid (FaSSIF), and fed state simulated intestinal fluid (FeSSIF) are commonly used. The use of FaSSIF and FeSSIF is particularly important for poorly water-soluble compounds because they simulate the solubilizing environment of mixed micelles. They comprise a bile salt (sodium taurocholate) and lecithin (phosphatidylcholine), which are responsible for the emulsification and absorption of dietary fats in humans and animals $[13,14]$.

Some researchers have reported that hydrate formation is the main cause of changes in dissolution characteristics and clinical failure of some compounds, including carbamazepine [1]. These authors tested this drug using a channel flow cell and simulated gastrointestinal fluids as a dissolution medium. They concluded that dissolution studies of solids that are capable of hydrate formation are complex and cannot be completely understood simply by measuring the dissolved concentration. For these drugs, they suggest that dissolution studies must be initiated in a physiologically representative medium to determine an appropriate in vitro-in vivo relationship. On the contrary, some researchers studied generic suspensions of benzoyl metronidazole [15] and metronidazole benzoate [16]. Although both groups used $900 \mathrm{ml}$ of $0.1 \mathrm{~N}$ hydrochloric acids as dissolution medium, one group used a USP paddle apparatus at $75 \mathrm{rpm}$ and the other used a USP basket apparatus at $100 \mathrm{rpm}$. Differences in dissolution profiles were found by both groups. Others have studied the in vivo release of carbamazepine using different dissolution medium and agitation 
rates [2]. The optimal conditions were used of a USP paddle apparatus at $50 \mathrm{rpm}$ with SGF without pepsin as the dissolution medium. Under these conditions, only one drug product (of four studied) was considered similar to the reference product $\left(f_{2}>50\right)$.

The flow-through cell method (USP Apparatus 4) is an alternative dissolution apparatus $[17,18]$. Its advantages over USP Apparatuses 1 and 2 have been widely demonstrated, especially for the study of the in vitro dissolution performance of poorly water-soluble drugs $[19,20]$. The flow-through cell apparatus permits continuous extraction of the drug, simulating absorption into the systemic circulation, generating an intermittent flow of the dissolution medium into the cell where the dosage form is placed [21]. It can be used as an open system, allowing release under sink conditions, which facilitates the dissolution of poorly soluble drugs as well as changing the dissolution medium within a pH range of physiological relevance [22]. USP Apparatus 4 has been used with FaSSIF, FeSSIF, and fasted state simulated gastric fluid (FaSSGF) to evaluate the in vitro dissolution profiles of troglitazone tablets [23]. Additionally, the flow-through cell method has been used to obtain significant in vitro-in vivo correlations under fasted and fed state conditions for immediate-release danazol capsules [19] and for modified-release diclofenac sodium pellets [24]. All of these drugs have solubility problems.

Despite the advantages of the flow-through cell apparatus over the USP basket and paddle apparatuses, little information is available of the in vitro release of carbamazepine and benzoyl metronidazole using the USP Apparatus 4 and simulated gastrointestinal fluids. The aim of this study was to quantify the in vitro release of both drugs from reference and generic formulations, using the flow-through cell apparatus and SGF with and without pepsin, SIF without pancreatin, and FaSSIF. The dissolution profiles of the reference and generic formulations obtained were compared using model-independent and dependent approaches.

\section{MATERIALS AND METHODS}

\section{Reagents and drug products}

Benzoyl metronidazole, carbamazepine, lecithin, pepsin, and sodium taurocholate were purchased from Sigma-Aldrich Co. (St. Louis MO, USA). Ethanol, hydrochloric acid, potassium chloride, sodium hydroxide, potassium phosphate monobasic were purchased from J. T. Baker-Mexico. The Tegretol ${ }^{\circledR}$ tablets (Novartis Farmaceutica S. A. de C. V., Mexico) and Flagy ${ }^{\circledR}$ suspension (Sanofi-Aventis de Mexico, S. A. de C. V., Mexico), containing carbamazepine $(200 \mathrm{mg})$ and benzoyl metronidazole $(250 \mathrm{mg} / 5 \mathrm{ml})$, respectively, were used. The Mexican health authorities (COFEPRIS) have established these brands as reference drug products [25]. A generic formulation of each containing the same dose was also used. Content uniformity of the carbamazepine tablets was determined, and assays for both drugs were performed on all products, according to the procedures described in the USP [9].

\section{Dissolution studies}

Dissolution profiles for carbamazepine and benzoyl metronidazole were obtained using an automated flow-through cell apparatus (Sotax CE6, Sotax AG, Switzerland) with 22.6-mm cells (i.d.) and a piston pump (Sotax CY7-50, Sotax AG, Switzerland). In all experiments, laminar flow (with a bed of $6 \mathrm{~g}$ of glass beads) at $37.0 \pm 0.5^{\circ} \mathrm{C}$ was used. SGF with and without pepsin and SIF at pH 6.8 without pancreatin were prepared according to the USP procedure [9]. FaSSIF at pH 6.5 was prepared according to a previous report, which evaluated its use for predicting the in vivo performance of Class I and II drugs [26]. All deareated simulated gastrointestinal fluids were pumped at a flow rate of $16 \mathrm{ml} / \mathrm{min}$, excepting FaSSIF, which was pumped at $8 \mathrm{ml} / \mathrm{min}$. An open system was used, without recycling the dissolution medium. Sequential sampling using nitrocellulose filters (Millipore) was performed every 5 min until 60 min, with six replicates. For every trial, standard calibration curves were used for each drug. Standard solutions of carbamazepine and benzoyl metronidazole $(1 \mathrm{mg} / \mathrm{ml})$ in ethanol were prepared separately by serial dilutions of stock solutions in SGF with and without pepsin, SIF without pancreatin and FaSSIF to achieve concentrations of $10-25 \mu \mathrm{g} / \mathrm{ml}$ of carbamazepine and $50-80 \mu \mathrm{g} / \mathrm{ml}$ of benzoyl metronidazole.

\section{Data analysis}

The dissolution profiles of the generic drug products versus the reference products were compared by model-independent anddependent-approaches. For model-independent comparisons, the mean dissolution time (MDT) and dissolution efficiency (DE) were calculated. Furthermore, the percentage of drug dissolved at $60 \mathrm{~min}$ was compared. Mean values were compared using Student's $t$-test. Differences were considered significant if $* \mathrm{P}<0.05$. For calculation of DE and MDT values, the Excel add-in DDSolver was used [27]. For model-dependent comparisons, dissolution data were fitted to firstorder, Higuchi, Korsmeyer-Peppas, Hixson-Crowell, Peppas-Sahlin, Weibull, and logistic models. The model with the highest adjusted determination coefficient ( $\mathrm{R}^{2}$ adjusted $)$ and the minimum Akaike information criterion (AIC) was chosen as the best fit model [28]. Data analysis was performed using the Excel add-in DDSolver. Additionally, dissolution data were fitted to a single rectangular hyperbola model: $y=a x / b+x$ using SigmaPlot software (version 11.0). The $\mathrm{t}_{10 \%}, \mathrm{t}_{25 \%}, \mathrm{t}_{50 \%}$ and $\mathrm{t}_{63.2 \%}$ values were calculated using the $a$ and $b$ parameters. Reference and generic mean values were compared using Student's $t$-test. Differences were considered significant if ${ }^{*} \mathrm{P}<0.05$.
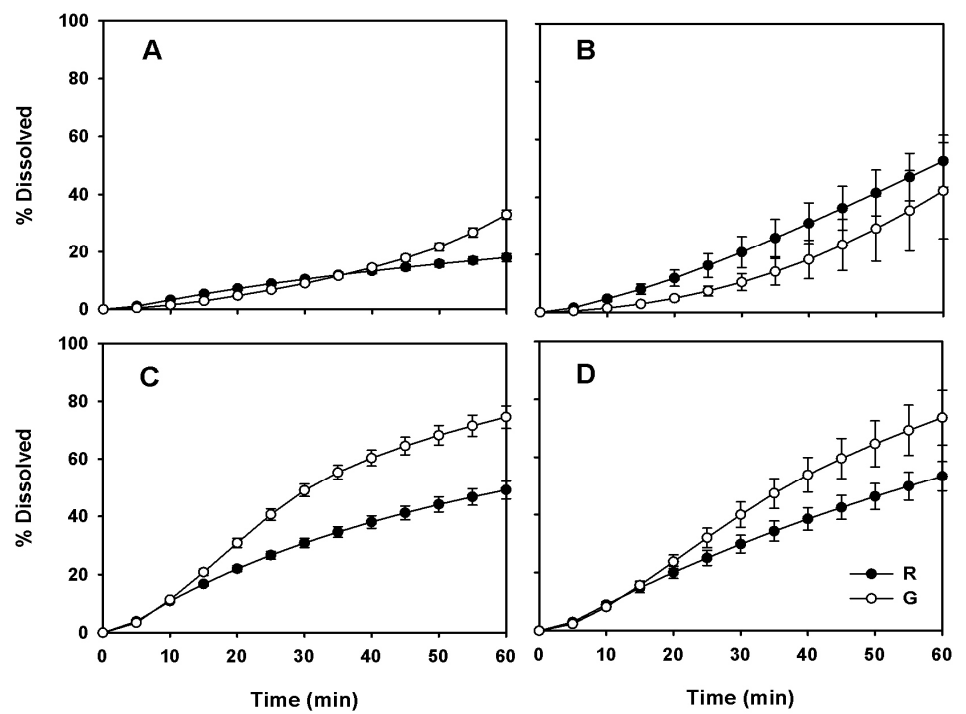

Fig. 1: Dissolution profiles of carbamazepine tablets, determined using the flow-through cell and simulated gastrointestinal fluids. A) SGF without pepsin, B) SGF with pepsin, C) SIF without pancreatin, and D) FaSSIF. Reference (R) and generic (G) formulations. mean \pm SD, $n=6$ 

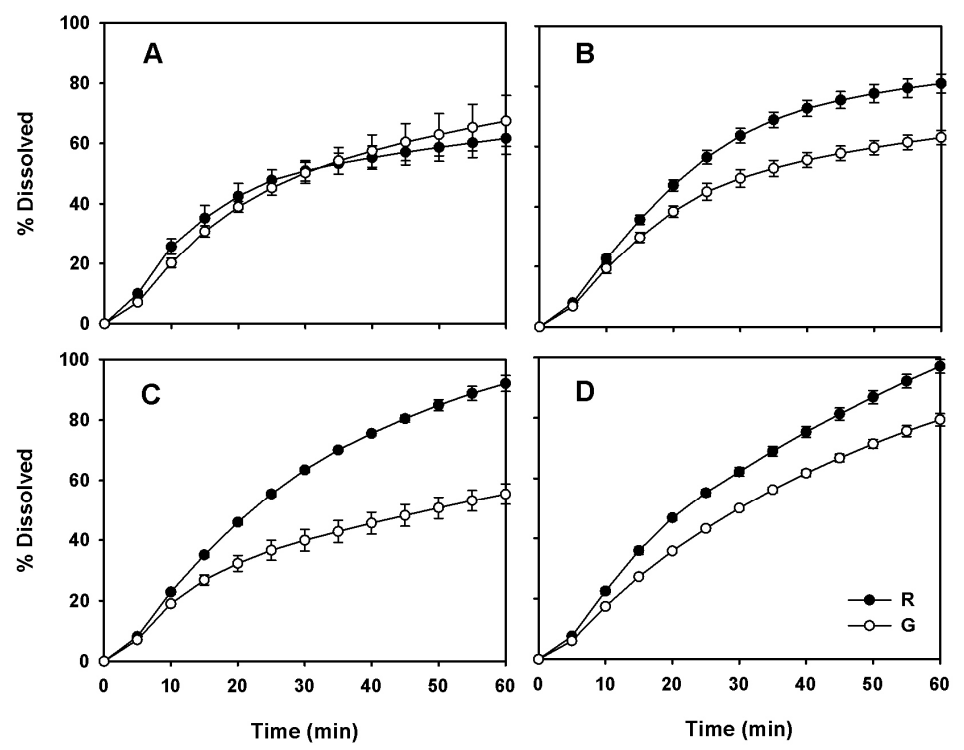

Fig. 2: Dissolution profiles of benzoyl metronidazole suspensions, determined using the flow-through cell and simulated gastrointestinal fluids. A) SGF without pepsin, B) SGF with pepsin, C) SIF without pancreatin, and D) FaSSIF. Reference (R) and generic (G) formulations. mean $\pm S D, n=6$

\section{RESULTS AND DISCUSSION}

Both carbamazepine drug products met the requirements of the content uniformity test, and the carbamazepine and benzoyl metronidazole drug products met the requirements of the assay tests specified in the USP. In the content uniformity test, carbamazepine $(n=10)$ ranged from 99.06 to $105.09 \%$ (reference) and 97.94 to $106.58 \%$ (generic). In the assay test, the results for carbamazepine $(\mathrm{n}=3$ ) were $101.41 \pm 2.31 \%$ (reference) and $101.88 \pm 1.96 \%$ (generic), whereas those for benzoyl metronidazole were $102.37 \pm 2.89 \%$ (reference) and $99.57 \pm 3.21 \%$ (generic). All values are shown as the mean \pm SD.

\section{Dissolution profiles}

The dissolution profiles of carbamazepine tablets and benzoyl metronidazole suspension, determined using the flow-through cell apparatus and simulated gastrointestinal fluids, are shown in fig. 1 and fig. 2, respectively.

The carbamazepine generic and reference drug products showed limited dissolution in SGF without pepsin $(<35 \%)$, likely due to its low solubility, the $\mathrm{pH}$ of the medium, and the absence of pepsin. Thus, SGF without pepsin is lacking discriminative capability for carbamazepine reference and generic products. Better in vitro release of carbamazepine was observed in SGF with pepsin, SIF without pancreatin, and FaSSIF. Previous reports showed significant differences in carbamazepine plasma levels of healthy volunteers [29] and in serum levels of patients using this drug [30]. An adequate dissolution test allows differentiation between drug products before clinical problems occur. The flow-through cell method (16 ml/min) with $1.0 \%$ sodium lauryl sulphate aqueous solution as dissolution medium was reported to be more discriminative for carbamazepine generic products than the use of USP Apparatus 2 [31]. In another report, rapid dissolution was observed when several carbamazepine formulations were tested under official conditions (USP basket apparatus and 1.0\% sodium lauryl sulphate aqueous solution); however, SIF showed better discriminative capability between drug products [32].

Otherwise, the slow rate of metronidazole absorption from tablets was reported to be associated with the slow dissolution in the USP basket apparatus at $100 \mathrm{rpm}$ using $0.1 \mathrm{~N}$ hydrochloric acids as dissolution medium [33]. Other researchers have reported variations in absorption, lack of bioequivalence, and ineffective treatment due to low drug levels [34]. Benzoyl metronidazole has a bioavailability of approximately $80 \%$. Based on its solubility and absorption characteristics, it is classified as a Class IV drug. The dissolution of Class IV drugs is dependent on nature of the drug (acid or basic), its solubility, and formulation factors. Consequently, drugs with this class may have problems with dissolution, which can restrict in vivo absorption [2].

Some researchers have reported that fluids in the fasted state stomach typically have a $\mathrm{pH}<2$, but ranging from $\mathrm{pH} 1-7.5$. Food intake results in an almost instantaneous increase of the gastric $\mathrm{pH}$. Depending on the content of the meal, the fed-state gastric $\mathrm{pH}$ increases to between 4 and 7. Soon after food intake, the gastric $\mathrm{pH}$ gradually returns to the fasted state $\mathrm{pH}$. The mean fasted-state $\mathrm{pH}$ in the proximal small intestine is approximately 6.5 [12]. This information is valuable when the dissolution medium for an in vitro release study is chosen. Research should focus on the establishment of discriminative dissolution tests to guide the development of a formulation with optimal bioavailability. We found that the USP Apparatus 4 and SIF without pancreatin allowed differentiation between the reference and generic formulations of carbamazepine and benzoyl metronidazole.

Some conditions showed slow in vitro release of carbamazepine and benzoyl metronidazole from tablets and suspension, respectively. Some researchers have suggested that this result can be explained by the hydrodynamic conditions that characterize the flow-through cell apparatus, which lacks an agitation mechanism, and by the fact that the dosage form and the drug particles are continuously exposed to uniform laminar flow, similar to the natural environment of the gastrointestinal tract, causing a different dissolution pattern [35]. When using the USP Apparatus 4, cell size, glass bead type, and flow rate are critical factors in determining the dissolution pattern. Flow rates of 8 and $16 \mathrm{ml} / \mathrm{min}$ are suggested by the European and US Pharmacopeia [36]. When the flow rate of the dissolution medium is $16 \mathrm{ml} / \mathrm{min}$, fluid flow inside the $22.6-\mathrm{mm}$ cells is 4 $\mathrm{cm} / \mathrm{min}$ [37]. Fotaki et al. [37] reported that the axial velocity of the intestinal fluid is approximately $1.5 \mathrm{~cm} / \mathrm{min}$. Therefore, the axial velocity of $4 \mathrm{~cm} / \mathrm{min}$ generated under the experimental conditions described above is close to reported physiological parameters.

\section{Model-independent comparisons}

Mean values \pm standard error of the mean (SEM) of percentage dissolved at $60 \mathrm{~min}$ and model-independent parameters MDT and DE are shown in table 1 . In most comparisons, significant differences were observed between the generic and reference formulations of carbamazepine and benzoyl metronidazole $\left({ }^{*} \mathrm{P}<0.05\right)$. Differences in the three parameters used to compare dissolution profiles were observed for carbamazepine in SGF without pepsin and FaSSIF, whereas for benzoyl metronidazole differences were only observed in SIF without pancreatin. 
Table 1: Model-independent parameters of carbamazepine and benzoyl metronidazole

\begin{tabular}{|c|c|c|c|c|c|}
\hline Drug & Medium & Code & Diss. at $60 \mathrm{~min}(\%)$ & MDT (min) & DE (\%) \\
\hline \multirow[t]{8}{*}{$\mathrm{CM}$} & A & $\mathrm{R}$ & $17.99 \pm 0.58$ & $27.25 \pm 0.37$ & $9.81 \pm 0.30$ \\
\hline & & $\mathrm{G}$ & $33.00 \pm 0.67 *$ & $39.68 \pm 0.29 *$ & $11.17 \pm 0.28 *$ \\
\hline & $\mathrm{B}$ & $\mathrm{R}$ & $52.55 \pm 3.67$ & $34.27 \pm 1.17$ & $22.57 \pm 1.86$ \\
\hline & & $\mathrm{G}$ & $42.26 \pm 6.82$ & $39.77 \pm 0.53 *$ & $14.06 \pm 2.01^{*}$ \\
\hline & $\mathrm{C}$ & $\mathrm{R}$ & $49.16 \pm 1.26$ & $25.38 \pm 0.15$ & $28.36 \pm 0.63$ \\
\hline & & $\mathrm{G}$ & $74.55 \pm 1.61^{*}$ & $25.56 \pm 0.25$ & $42.77 \pm 0.81^{*}$ \\
\hline & $\mathrm{D}$ & $\mathrm{R}$ & $53.31 \pm 2.08$ & $28.19 \pm 0.18$ & $28.28 \pm 1.15$ \\
\hline & & $\mathrm{G}$ & $73.66 \pm 3.88^{*}$ & $29.19 \pm 0.39 *$ & $37.74 \pm 1.72 *$ \\
\hline \multirow[t]{8}{*}{$\mathrm{BM}$} & A & $\mathrm{R}$ & $61.68 \pm 2.16$ & $17.18 \pm 0.51$ & $43.98 \pm 1.37$ \\
\hline & & $\mathrm{G}$ & $67.47 \pm 3.44$ & $20.77 \pm 0.86^{*}$ & $43.90 \pm 1.39$ \\
\hline & B & $\mathrm{R}$ & $80.94 \pm 1.28$ & $19.97 \pm 0.14$ & $54.00 \pm 0.85$ \\
\hline & & $\mathrm{G}$ & $62.98 \pm 0.98^{*}$ & $19.71 \pm 0.27$ & $42.29 \pm 0.71^{*}$ \\
\hline & $\mathrm{C}$ & $\mathrm{R}$ & $92.09 \pm 1.08$ & $23.24 \pm 0.30$ & $56.40 \pm 0.34$ \\
\hline & & $\mathrm{G}$ & $55.41 \pm 1.39 *$ & $21.18 \pm 0.39 *$ & $35.86 \pm 1.03^{*}$ \\
\hline & $\mathrm{D}$ & $\mathrm{R}$ & $97.09 \pm 1.31$ & $24.81 \pm 0.17$ & $56.94 \pm 0.75$ \\
\hline & & $\mathrm{G}$ & $79.42 \pm 1.19^{*}$ & $25.31 \pm 0.14$ & $45.92 \pm 0.51^{*}$ \\
\hline
\end{tabular}

CM: carbamazepine, BM: benzoyl metronidazole, A: SGF without pepsin, B: SGF with pepsin, C: SIF without pancreatin, D: FaSSIF, R: reference, G: generic, MDT: mean dissolution time, DE: dissolution efficiency. mean $\pm \mathrm{SEM}, \mathrm{n}=6$. ${ }^{*} \mathrm{P}<0.05$

According to previous reports, carbamazepine dihydrate showed a dissolution of $36.74 \%$ in FaSSGF at $60 \mathrm{~min}$ [38]; five benzoyl metronidazole suspensions in SGF without pepsin showed DE values of 56.60-93.96\% in $90 \mathrm{~min}$, using the USP Apparatus 2 at $50 \mathrm{rpm}$ [2].

The model-independent parameters MDT and DE are commonly used to compare dissolution profiles. MDT represents the average time at which $63.2 \%$ of the dose is dissolved, and DE relates the area under the curve of the dissolution profile to the total area of the rectangle formed by the theoretical dissolution of $100 \%$ of the dose and the time interval of the test. MDT and DE have been also proposed as satisfactory parameters for in vitro-in vivo correlation (IVIVC) levels B and C [39]. Level B is defined as the relationship between MDT and mean residence time (average time that a molecule stays in the body), and both parameters are calculated by statistical moments analysis. Level $\mathrm{C}$ is defined as the association between a dissolution time point $\left(\mathrm{t}_{50 \%}, \mathrm{t}_{85 \%}\right.$, etc.) and one pharmacokinetic parameter, such as area under the curve, $\mathrm{C}_{\max }$, or $\mathrm{T}_{\max }$. DE is used by some researchers as an appropriate parameter to expresses the global drug dissolution performance, useful for comparison of dissolution profiles [40] or to relate it to some in vivo parameter.

\section{Model-dependent comparisons}

The adjusted coefficient of determination ( $\mathrm{R}^{2}$ adjusted) and the AIC mean values for carbamazepine and benzoyl metronidazole are shown in table 2 and table 3, respectively.

Table 2: Criteria used for the selection of the best fit model for the carbamazepine data

\begin{tabular}{|c|c|c|c|c|c|c|c|c|}
\hline Medium & Code & First-order & Higuchi & Korsmeyer-Peppas & Hixson-Crowell & Peppas-Sahlin & Weibull & Logistic \\
\hline \multicolumn{9}{|l|}{$\mathrm{R}^{2}$ adjusted } \\
\hline \multirow[t]{2}{*}{ A } & $\mathrm{R}$ & 0.9903 & 0.8623 & 0.9530 & 0.9879 & 0.9899 & 0.9641 & 0.9739 \\
\hline & $\mathrm{G}$ & 0.8370 & 0.5924 & 0.9904 & 0.8495 & 0.9523 & 0.9840 & 0.9725 \\
\hline \multirow[t]{2}{*}{ B } & $\mathrm{R}$ & 0.8993 & 0.7040 & 0.9825 & 0.9208 & 0.9863 & 0.9862 & 0.9832 \\
\hline & $\mathrm{G}$ & 0.7992 & 0.5753 & 0.9919 & 0.8212 & 0.9520 & 0.9825 & 0.9690 \\
\hline \multirow[t]{2}{*}{$\mathrm{C}$} & $\mathrm{R}$ & 0.9941 & 0.8970 & 0.9479 & 0.9870 & 0.9841 & 0.9826 & 0.9961 \\
\hline & $\mathrm{G}$ & 0.9634 & 0.8499 & 0.8727 & 0.9792 & 0.9608 & 0.9778 & 0.9976 \\
\hline \multirow[t]{2}{*}{ D } & $\mathrm{R}$ & 0.9897 & 0.8461 & 0.9628 & 0.9957 & 0.9946 & 0.9926 & 0.9990 \\
\hline & $\mathrm{G}$ & 0.9308 & 0.7963 & 0.9442 & 0.9584 & 0.9890 & 0.9930 & 0.9963 \\
\hline \multicolumn{9}{|l|}{$\mathrm{AIC}$} \\
\hline \multirow[t]{2}{*}{ A } & $\mathrm{R}$ & 14.60 & 47.82 & 33.85 & 17.32 & 16.96 & 31.62 & 27.65 \\
\hline & $\mathrm{G}$ & 65.31 & 76.36 & 30.29 & 64.35 & 51.98 & 37.80 & 44.51 \\
\hline \multirow[t]{2}{*}{ B } & $\mathrm{R}$ & 69.31 & 83.76 & 39.16 & 65.90 & 36.40 & 36.19 & 39.59 \\
\hline & $\mathrm{G}$ & 72.66 & 82.21 & 30.29 & 71.39 & 57.40 & 43.31 & 51.15 \\
\hline \multirow[t]{2}{*}{ C } & $\mathrm{R}$ & 32.18 & 67.86 & 60.52 & 42.13 & 46.94 & 47.07 & 25.65 \\
\hline & $\mathrm{G}$ & 67.45 & 84.60 & 83.40 & 60.83 & 69.94 & 61.65 & 28.57 \\
\hline \multirow[t]{2}{*}{ D } & $\mathrm{R}$ & 42.15 & 75.40 & 59.21 & 31.58 & 36.51 & 39.36 & 15.92 \\
\hline & $\mathrm{G}$ & 74.40 & 88.18 & 73.25 & 67.74 & 53.85 & 45.25 & 23.34 \\
\hline
\end{tabular}

A: SGF without pepsin, B: SGF with pepsin, C: SIF without pancreatin, D: FaSSIF, R: reference, G: generic. Mean, $n=6$

The dissolution data for the carbamazepine reference and generic formulations were well fitted to the logistic model $\left(\mathrm{R}^{2}\right.$ adjusted $\left.>0.9961\right)$ when using SIF without pancreatin and FaSSIF as the dissolution mediums. The $\beta$ values of this model for the reference and generic formulations, respectively, were $2.75 \pm 0.02$ and $4.10 \pm 0.06$ using SIF without pancreatin and $3.18 \pm 0.08$ and $4.37 \pm 0.20$ using FaSSIF. These data were used to compare dissolution profiles, and significant differences in the generic formulation were found in both simulated fluids $\left({ }^{*} \mathrm{P}<0.05\right)$. Inconsistent fitting using SGF with and without pepsin was found for both formulations. In contrast, the data for the benzoyl metronidazole reference and generic formulations were well fitted by logistic model $\left(\mathrm{R}^{2}\right.$ adjusted $\left.>0.9551\right)$, but using SGF with and without pepsin as the dissolution media. The $\beta$ values of this model for the reference and generic formulations, respectively, were $2.33 \pm 0.06$ and $2.96 \pm 0.19$ in SGF without pepsin and $3.63 \pm 0.06$ and $2.82 \pm 0.06$ in SGF with pepsin. Significant differences in the generic formulation were found in both simulated fluids $\left({ }^{*} \mathrm{P}<0.05\right)$. Inconsistent fitting using SIF without pancreatin and FaSSIF was found for both benzoyl metronidazole formulations. None of the carbamazepine and benzoyl metronidazole data was well fitted by the Higuchi or Peppas-Sahlin models. 
Table 3: Criteria used for the selection of the best fit model for the benzoyl metronidazole data

\begin{tabular}{|c|c|c|c|c|c|c|c|c|}
\hline Medium & Code & First-order & Higuchi & Korsmeyer-peppas & Hixson-crowell & Peppas-sahlin & Weibull & Logistic \\
\hline \multicolumn{9}{|l|}{$\mathrm{R}^{2}$ adjusted } \\
\hline \multirow[t]{2}{*}{$A$} & $\mathrm{R}$ & 0.7877 & 0.9221 & 0.8499 & 0.6960 & 0.9082 & 0.9167 & 0.9551 \\
\hline & $\mathrm{G}$ & 0.9422 & 0.9326 & 0.8622 & 0.9053 & 0.9393 & 0.9547 & 0.9819 \\
\hline \multirow[t]{2}{*}{ B } & $\mathrm{R}$ & 0.9813 & 0.9180 & 0.8193 & 0.9592 & 0.9193 & 0.9720 & 0.9963 \\
\hline & $\mathrm{G}$ & 0.9314 & 0.9285 & 0.8211 & 0.8853 & 0.9194 & 0.9326 & 0.9707 \\
\hline \multirow[t]{2}{*}{$\mathrm{C}$} & $\mathrm{R}$ & 0.9753 & 0.9173 & 0.9723 & 0.9932 & 0.9658 & 0.9967 & 0.9856 \\
\hline & $\mathrm{G}$ & 0.9133 & 0.9577 & 0.9079 & 0.8696 & 0.9579 & 0.9597 & 0.9801 \\
\hline \multirow[t]{2}{*}{ D } & $\mathrm{R}$ & 0.8986 & 0.9108 & 0.9414 & 0.9857 & 0.9782 & 0.9881 & 0.9514 \\
\hline & $\mathrm{G}$ & 0.9829 & 0.8968 & 0.9426 & 0.9968 & 0.9830 & 0.9965 & 0.9947 \\
\hline \multicolumn{9}{|l|}{ AIC } \\
\hline \multirow[t]{2}{*}{ A } & $\mathrm{R}$ & 77.50 & 65.75 & 74.84 & 82.08 & 69.57 & 67.24 & 59.19 \\
\hline & $\mathrm{G}$ & 64.80 & 68.73 & 78.03 & 68.47 & 68.70 & 62.30 & 50.06 \\
\hline \multirow[t]{2}{*}{ B } & $\mathrm{R}$ & 59.22 & 77.17 & 87.47 & 68.38 & 78.54 & 64.65 & 36.34 \\
\hline & $\mathrm{G}$ & 67.83 & 68.05 & 79.86 & 74.06 & 70.98 & 68.00 & 57.70 \\
\hline \multirow[t]{2}{*}{ C } & $\mathrm{R}$ & 65.46 & 80.15 & 78.90 & 49.56 & 70.82 & 40.38 & 56.53 \\
\hline & $\mathrm{G}$ & 65.29 & 56.90 & 66.21 & 70.38 & 57.84 & 56.30 & 47.98 \\
\hline \multirow[t]{2}{*}{ D } & $\mathrm{R}$ & 80.60 & 82.03 & 77.76 & 59.92 & 66.53 & 57.50 & 74.05 \\
\hline & $\mathrm{G}$ & 57.65 & 79.51 & 73.32 & 37.65 & 59.44 & 39.48 & 44.08 \\
\hline
\end{tabular}

A: SGF without pepsin, B: SGF with pepsin, C: SIF without pancreatin, D: FaSSIF, R: reference, G: generic. Mean, $\mathrm{n}=6$

Table 4: Model-dependent parameters of carbamazepine and benzoyl metronidazole

\begin{tabular}{|c|c|c|c|c|c|c|}
\hline Drug & Medium & Code & $\mathbf{R}^{2}$ & $\mathrm{t}_{10 \%}(\mathrm{~min})$ & $\mathbf{t}_{25 \%}$ (min) & $\mathbf{t}_{50 \%}(\mathrm{~min})$ \\
\hline \multirow[t]{9}{*}{$\overline{\mathrm{CM}}$} & \multirow[t]{2}{*}{$A$} & $\mathrm{R}$ & 0.9957 & $30.01 \pm 1.44$ & $96.78 \pm 5.73$ & $404.36 \pm 56.54$ \\
\hline & & $\mathrm{G}$ & 0.8723 & $23.56 \pm 0.54^{*}$ & $58.90 \pm 1.36^{*}$ & $117.79 \pm 2.72 *$ \\
\hline & \multirow[t]{2}{*}{ B } & $\mathrm{R}$ & 0.9533 & $12.94 \pm 1.20$ & $32.34 \pm 3.0$ & $64.68 \pm 6.0$ \\
\hline & & G & 0.8567 & $20.23 \pm 2.63^{*}$ & $50.58 \pm 6.57^{*}$ & $101.15 \pm 13.14^{*}$ \\
\hline & \multirow[t]{2}{*}{$\mathrm{C}$} & $\mathrm{R}$ & 0.9966 & $8.36 \pm 0.16$ & $23.69 \pm 0.61$ & $61.11 \pm 2.70$ \\
\hline & & G & 0.9791 & $5.69 \pm 0.13^{*}$ & $15.11 \pm 0.33^{*}$ & $33.70 \pm 0.80 *$ \\
\hline & \multirow[t]{3}{*}{ D } & $\mathrm{R}$ & 0.9969 & $9.78 \pm 0.48$ & $25.58 \pm 1.25$ & $55.43 \pm 2.73$ \\
\hline & & G & 0.9861 & $7.71 \pm 0.36^{*}$ & $19.43 \pm 0.91^{*}$ & $39.45 \pm 1.88^{*}$ \\
\hline & & & & $\mathrm{t}_{25 \%}(\mathrm{~min})$ & $\mathrm{t}_{50 \%}(\mathrm{~min})$ & $\mathrm{t}_{63.2 \%}(\mathrm{~min})$ \\
\hline \multirow[t]{8}{*}{ BM } & \multirow[t]{2}{*}{ A } & $\mathrm{R}$ & 0.9788 & $9.24 \pm 0.50$ & $31.82 \pm 2.43$ & $68.51 \pm 11.38$ \\
\hline & & G & 0.9867 & $11.42 \pm 0.30^{*}$ & $32.26 \pm 1.57$ & $53.11 \pm 4.65$ \\
\hline & \multirow[t]{2}{*}{ B } & $\mathrm{R}$ & 0.9774 & $8.92 \pm 0.20$ & $22.53 \pm 0.58$ & $33.08 \pm 0.96$ \\
\hline & & G & 0.9785 & $11.54 \pm 0.28 *$ & $33.71 \pm 1.10^{*}$ & $56.39 \pm 2.41^{*}$ \\
\hline & \multirow[t]{2}{*}{$\mathrm{C}$} & $\mathrm{R}$ & 0.9926 & $9.69 \pm 0.12$ & $22.59 \pm 0.19$ & $31.29 \pm 0.26$ \\
\hline & & G & 0.9909 & $14.57 \pm 0.66^{*}$ & $48.71 \pm 3.46^{*}$ & $97.26 \pm 11.21^{*}$ \\
\hline & \multirow[t]{2}{*}{ D } & $\mathrm{R}$ & 0.9949 & $10.08 \pm 0.15$ & $22.89 \pm 0.37$ & $31.17 \pm 0.55$ \\
\hline & & $\mathrm{G}$ & 0.9962 & $13.41 \pm 0.12^{*}$ & $30.71 \pm 0.40^{*}$ & $42.03 \pm 0.66^{*}$ \\
\hline
\end{tabular}

CM: carbamazepine, BM: benzoyl metronidazole, A: SGF without pepsin, B: SGF with pepsin, C: SIF without pancreatin, D: FaSSIF, R: reference, G: generic. mean $\pm \mathrm{SEM}, \mathrm{n}=6 .{ }^{*} \mathrm{P}<0.05$

Some authors reported that the Weibull model best fit the release kinetics of five benzoyl metronidazole commercial products (oral suspensions). All $\beta$ values were $<1$, which indicates a parabolic curve with initial inflection. The dissolution conditions used were $900 \mathrm{ml}$ of SGF without pepsin, a USP paddle apparatus at $50 \mathrm{rpm}$, and 90 min of testing [2].

Additionally, the single rectangular hyperbola equation $(y=a x / b+x)$ was used to fit the dissolution data for carbamazepine and benzoyl metronidazole drug products, where $x$ is the time of the test, $y$ is the percentage dissolved at time t and $a$ and $b$ are constants. With $a$ and $b$ parameters, the $t_{10 \%}, t_{25 \%}, t_{50 \%}$ and $t_{63.2 \%}$ values were easily calculated. The coefficient of determination $\left(\mathrm{R}^{2}\right)$ and the $t_{x} \%$ mean values \pm SEM of both drugs using different simulated gastrointestinal fluids are shown in table 4.

The carbamazepine reference product released approximately $50 \%$ of the dose at $60 \mathrm{~min}$ in three of the four simulated gastrointestinal fluids, and the $t_{10 \%}, t_{25 \%}$ and $t_{50 \%}$ data were calculated. These values were taken as the dissolution rate parameters and compared. Significant differences were found between the reference and generic formulations in all gastrointestinal fluids $\left({ }^{*} \mathrm{P}<0.05\right)$. As previously discussed, owing to the limited dissolution of carbamazepine in SGF without pepsin, this simulated fluid does not have the discriminative capability for carbamazepine formulations.
However, as the benzoyl metronidazole reference product showed almost $100 \%$ released at $60 \mathrm{~min}, \mathrm{t}_{25 \%}, \mathrm{t}_{50 \%}$ and $\mathrm{t}_{63.2 \%}$ were calculated. When the dissolution profiles were compared, significant differences were found between the reference and generic formulations $\left({ }^{*} \mathrm{P}<0.05\right)$, except for the $\mathrm{t}_{50 \%}$ and $\mathrm{t}_{63.2 \%}$ values, when SGF without pepsin was used $\left({ }^{*} \mathrm{P}>0.05\right)$.

The $t_{x} \%$ and sampling time values are commonly used to characterize drug release rate. The $t_{x} \%$ value corresponds to the time necessary to release a determined percentage of drug (e. g., $\mathrm{t}_{10 \%}, \mathrm{t}_{50 \%}, \mathrm{t}_{90 \%}$ ) and the sampling time corresponds to the amount of drug dissolved in that time (e. $g_{\text {., }} t_{10 \mathrm{~min}}, \mathrm{t}_{50 \mathrm{~min}}, \mathrm{t}_{90 \mathrm{~min}}$ ). Pharmacopeias use this parameter as an acceptance limit for the dissolution test (e. g., $\mathrm{t}_{45 \min } \geq 80 \%$ ) [41] As no official dissolution test has been defined for benzoyl metronidazole suspensions and since this is an immediate-release dosage form, some researchers have suggested a $Q$ value $\geq 80 \%$ and a dissolution time $\geq 60 \mathrm{~min}$ are adequate dissolution criteria [2].

Because little information is available on carbamazepine tablets and benzoyl metronidazole suspensions under the hydrodynamic environment generated by the USP Apparatus 4, additional research is necessary. Some authors have suggested optimization of the flowthrough cell to obtain reliable and discriminative results reflecting the major as well as the minor formulation variables prior to bioequivalence testing [21]. Finally, it is important to emphasize that 
this is the first in vitro release study of carbamazepine tablets and benzoyl metronidazole suspension using the flow-through cell apparatus and bio-relevant media. Reference and generic formulations were found to show significant differences. The clinical impact of these results should be evaluated using appropriate clinical protocols

\section{CONCLUSION}

Characterization of the in vitro release of carbamazepine tablets and benzoyl metronidazole suspensions using the flow-through cell apparatus and simulated gastrointestinal fluids revealed significant differences in the rate and extent of dissolution of both drugs in the generic and reference formulations. Given the physicochemical characteristics of carbamazepine and benzoyl metronidazole and the environment in which the formulations were tested, these differences could be of clinical relevance.

\section{CONFLICT OF INTERESTS}

All authors have none to declare

\section{REFERENCES}

1. Lehto P, Aaltonen J, Tenho M, Rantanen J, Hirvonen J, Tanninen VP, et al. Solvent-mediated solid phase transformation of carbamazepine: effects of simulated intestinal fluid and fasted state simulated intestinal fluid. J Pharm Sci 2009;98:985-96.

2. Santos Da Silva A, Da Rosa Silva CE, Fávero P, Barcellos FE. Discriminative dissolution method for benzoyl metronidazole oral suspension. AAPS PharmSciTech 2015;17:778-86.

3. Namdev N. Formulation and evaluation of egg albumin-based controlled release microspheres of metronidazole. Int J Curr Pharm Res 2016;8:28-32.

4. Lindenberg M, Kopp S, Dressman JB. Classification of orally administered drugs on the World Health Organization model list of essential medicines according to the biopharmaceutics classification system. Eur J Pharm Biopharm 2004;58:265-78.

5. Kasim NA, Whitehouse M, Ramachandran C, Bermejo M, Lennernäs $\mathrm{H}$, Hussain AS, et al. Molecular properties of the WHO essential drugs and provisional biopharmaceutical classification. Mol Pharm 2004;1:85-96.

6. Dahan A, Miller JM, Amidon GL. Prediction of solubility and permeability class membership: provisional BCS classification of the world's top oral drugs. AAPS J 2009;11:740-6.

7. Therapeutic System Research Laboratories TSRL inc. Biopharmaceutics Classification System (BCS) Results. Available from: http://www.tsrlinc.net/search.cfm [Last accessed on 01 Apr 2017]

8. Kumar L, Deshpande A, Page A. Super generics/improved therapeutic entities: an approach to fulfil unmet medical needs and extending market exclusivity of generic medicines. Int J Pharm Pharm Sci 2015;7:25-9.

9. United States Pharmacopeia and National Formulary USP 40NF 35; The United States Pharmacopeial Convention, Inc: Rockville MD; 2017.

10. Zoeller T, Klein S. Simplified biorelevant media for screening dissolution performance of poorly soluble drugs. Dissolution Technol 2007;14:8-13.

11. Wang Q, Fotaki N, Mao Y. Biorelevant dissolution: methodology and application in drug development. Dissolution Technol 2009;16:6-12.

12. Marques MRC, Loebenberg R, Almukainzi M. Simulated biological fluids with possible application in dissolution testing. Dissolution Technol 2011;18:15-28.

13. Kloefer B, van Hoogevest P. Technical note: using biorelevant media with different types of orally administered formulations. Dissolution Technol 2010;17:46-7.

14. Marques M. Dissolution media simulating fasted and fed states. Dissolution Technol 2004;11:16.

15. Cárdenas HL, Cortés AR, Argotte R, Luna P, Domínguez A. Investigation of dissolution profiles from suspensions containing benzoyl metronidazole using a statistical model with repeated measurements. Drug Dev Ind Pharm 1994;20:1063-73.

16. Zietsman S, Kilian G, Worthington M, Stubbs C. Formulation development and stability studies of aqueous metronidazole benzoate suspensions containing various suspending agents. Drug Dev Ind Pharm 2007;33:191-7.

17. Singh I, Aboul-Enein HY. Advantages of USP apparatus IV (flowthrough cell apparatus) in dissolution studies. J Iran Chem Soc 2006;3:220-2.

18. Qui S, Wang K, Li M. In vitro dissolution studies of immediaterelease and extended release formulations using flow-through cell apparatus 4. Dissolution Technol 2014;21:6-15.

19. Sunesen VH, Pedersen BL, Kristensen HG, Müllertz A. In vivo in vitro correlations for a poorly soluble drug, danazol, using the flow-through dissolution method with bio-relevant dissolution media. Eur J Pharm Sci 2005;24:305-13.

20. Szymanska E, Winnicka K. Comparison of the flow-through cell and paddle methods for testing vaginal tablets containing a poorly water-soluble drug. Trop J Pharm Res 2013;12:39-44.

21. Emara LH, Emam MF, Taha NF, El-Ashmawy AA, Mursi NM. In vitro dissolution study of meloxicam immediate release products using flow-through cell (USP apparatus 4) under different operational conditions. Int J Pharm Pharm Sci 2014;6:254-60.

22. Fotaki N, Reppas C. The flow through cell methodology in the evaluation of intralumenal drug release characteristics. Dissolution Technol 2005;12:17-21.

23. Nicolaides E, Hempenstall JM, Reppas C. Biorelevant dissolution tests with the flow-through apparatus? Dissolution Technol 2000;7:1-4.

24. Jantratid E, De Maio V, Ronda E, Mattavelli V, Vertzoni M, Dressman JB. Application of biorelevant dissolution tests to the prediction of in vivo performance of diclofenac sodium from an oral modified-release pellet dosage form. Eur J Pharm Sci 2009;37:434-41.

25. Listado de Medicamentos de Referencia. Cofepris. Mexico. Available from: $\quad$ http://codigof.mx/medicamentos-de-referenciaactualizacion- $y$-lineamientos. [Last accessed on 21 Mar 2017]

26. Galia E, Nicolaides E, Hörter D, Löbenberg R, Reppas C, Dressman JB. Evaluation of various dissolution media for predicting in vivo performance of Class I and II drugs. Pharm Res 1998;15:698-705.

27. Zhang Y, Huo M, Zhou J, Zou A, Li W, Yao C, et al. DD solver: an add-in program for modeling and comparison of drug dissolution profiles. AAPS J 2010;12:263-71.

28. Yuksel N, Kanik AE, Baykara T. Comparison of in vitro dissolution profiles by ANOVA-based, model-dependent and independent methods. Int J Pharm 2000;209:57-67.

29. Olling M, Mensinga TT, Barends DM, Groen C, Lake OA, Meulenbelt J. Bioavailability of carbamazepine from four different products and the occurrence of side effects. Biopharm Drug Dispos 1999;20:19-28.

30. Rentmeester TW, Doelman JC, Hulsman JA. Carbamazepine: branded formulation versus generic formulation Pharmaceutish Weekbland 1990;125:1108-10.

31. Medina JR, Salazar DK, Hurtado M, Cortés AR, DomínguezRamírez AM. Comparative in vitro dissolution study of carbamazepine immediate-release products using the USP paddles method and the flow-through cell system. Saudi Pharm J 2014;22:141-7.

32. Girard ME, Millán R, Jung H, Torres S, Montoya MA. Dissolution study of carbamazepine tablets. Rev Mex Cienc Farm 1996;27:13-7.

33. Rediguieri CF, Porta V, Nunes DSG, Nunes TM, Junginger HE, Kopp S, et al. Biowaiver monographs for immediate release solid oral dosage forms: metronidazole. J Pharm Sci 2011;100:1618-27.

34. Medina JR, Ortiz HD, Hurtado M, Domínguez-Ramírez AM. Influence of dose and the USP basket and flow-through cell dissolution apparatus in the release kinetics of metronidazole immediate-release products. Int J Res Pharm Sci 2014;5:137-46.

35. Langenbucher F, Benz D, Kurth W, Moller H, Otz M. Standardized flow-cell method as an alternative to existing pharmacopoeial dissolution testing. Pharm Ind 1989;51:1276-81.

36. Steffansen B, Brodin B, Und Nielsen C. editors. Molecular Biopharmaceutics. ULLA Pharmacy Series. Pharmaceutical Press; 2010. 
37. Fotaki N, Symillides M, Reppas C. In vitro versus canine data for predicting input profiles of isosorbide-5-mononitrate from ora extended release products on a confidence interval basis. Eur J Pharm Sci 2005;24:115-22.

38. Bhise SB, Rajkumar. Influence of simulated gastrointestinal fluids on polymorphic behavior of anhydrous carbamazepine form III and biopharmaceutical relevance. PDA J Pharm Sci Technol 2010;64:28-36.

39. Demirtürk E, Öner L. In vitro-in vivo correlations. FABAD J Pharm Sci 2003;28:215-24.

40. Anderson NH, Bauer M, Boussac N, Khan-Malek R, Munden P, Sardaro M. An evaluation of fit factors and dissolution efficiency for the comparison of in vitro dissolution profiles. J Pharm Biomed Anal 1998;17:811-22.

41. Costa P, Sousa Lobo JM. Modelling and comparison of dissolution profiles. Eur J Pharm Sci 2001;13:123-33.

\section{How to cite this article}

- José Raúl Medina*, Jonathan Hernández, Marcela Hurtado. In vitro release studies of carbamazepine tablets and benzoyl metronidazole suspensions using the flow-through cell apparatus and simulated gastrointestinal fluids. Int J Appl Pharm 2017;9(4):54-60. 